\title{
Inappropriate Use of Antimicrobials and the Determinants among Patients Hospitalized in 3 Hospitals (Mizan, Bonga and Tepi) in Southwest Ethiopia Tadele Mekuriya Yadesa*
}

Department of Pharmacy, College of Medicine and Health Science, Ambo University, Ambo, Ethiopia

\begin{abstract}
Background: The spread of antimicrobial resistance in developing countries is associated with complex and interconnected factors. Accordingly, there is poor controlling system in use of all the available antimicrobials in the hospital. This facilitates for the spread of inappropriateness of prescribing ending up with emergence and spread of antimicrobial resistance.
\end{abstract}

Objective: The study aims to assess the inappropriateness of the use of antimicrobials and the associated factors among patients admitted in 3 hospitals in southwest Ethiopia.

Methods: A prospective observational study design was employed at medical wards of 3 hospitals in southwest Ethiopia. Data was analyzed using SPSS, version 16.0 using logistic regression model. Statistical significance was considered at $p$-value $<0.05$.

Results: A total of 348 antimicrobial containing orders were prescribed for the 291 patients during the 2525 person-days of follow up. At least one antimicrobial use problem was identified among most $(80.1 \%)$ of the patients. The multivariate logistic regression showed that the use of social drug $[A O R=2.549(1.279-5.080)$ at $95 \%$ C.I.; $p$ value $=0.008)]$, the use of antimicrobial in the previous 3 months $[A O R=4.095(1.855-9.040)$ at $95 \%$ C.I.; $p$ value $=0.000]$ and the total number of drugs used $[A O R=2.997(1.413-6.356) ; p$ value $=0.004$ for $3-4$ drugs and $A O R=4.653(1.985-$ 10.906); $p$ value $=0.000$ for $\geq 5$ drugs at $95 \%$ C.I.] were independently associated with antimicrobial use problems.

Conclusion: At least one antimicrobial use problem was prevalent among most of the patients. The independent determinants of antimicrobial use problems were the total number of drugs used, use of social drugs and the previous use of antimicrobials.

Keywords: Inappropriate use; Antimicrobials; Southwest; Ethiopia

\section{Introduction}

Although many of infectious diseases can be prevented with improved personal hygiene, immunization and environmental sanitation, antimicrobials are still the main therapy for many of them [1]. World Health Organization (WHO) estimated that $80 \%$ of antibiotics is used in the community, of which about $20-50 \%$ is used inappropriately. As a result, WHO recommended involvement of the community in tackling of antibiotic resistance through improving access to medical services, reducing unnecessary use of antibiotics, taking a full course of treatment, not sharing medications with other people, and not keeping part of the course for another occasion [2,3].

Without effective antimicrobial, diverse fields of medicine will be severely hampered, including surgery, the care of premature infants, cancer chemotherapy, care of the critically ill and transplantation medicine [4]. Inappropriate use of antimicrobials leads to produce drug resistance which is one of the major issues. Inappropriate use of antibiotics can result in bacteria resistant to antibiotics in the community. The acceleration of antibiotic resistance and the decline in the development of new antibiotics to combat the problem has created a significant public health challenges to health policy makers, health care workers, and the population around the world $[5,6]$.

Factors that promote the emergence of resistance include: frequent use of broad-spectrum antimicrobial agents, prolonged use of antimicrobial agents, more frequent use of invasive devices and procedures, large numbers of patients with complex medical problems in small areas within a hospital, and the presence of patients who require prolonged hospitalization [7]. Hospitals are considered an excellent compartment for the selection of resistant and Multi-Drug
Resistant (MDR) bacteria [8]. The number of unqualified medical practitioners in any society is a big contributor of antimicrobial misuse [9]. For one thing, non-adherence to the guidelines frequently results in more broad-spectrum empirical therapy [10]. Moreover, approximately $5 \%$ of hospitalized patients who were given antimicrobials experienced some adverse reactions to these drugs for which $20 \%$ required treatment [11].

The early switch from intravenous to oral treatment is feasible and also advantageous in: narrowing spectrum of action, preventing complications and containing costs [12]. Moreover, despite its requirement, the clinicians rarely define the type of infection and the presumable causative micro-organism before treating [13].

In developing countries, patients frequently waste scarce household resources on unnecessary antimicrobials therapy [14]. In these countries, antimicrobials are prescribed for $44-97 \%$ of hospitalized patients often unnecessarily or inappropriately [15]. Reasons for inappropriate antimicrobials prescriptions in hospitals include uncertainty of

*Corresponding authors: Tadele Mekuriya Yadesa, Lecturer and Clinical Pharmacy Specialist, Department of Pharmacy, College of Medicine and Health Science, Ambo University, Ambo, Ethiopia, Tel: +251471110331; E-mail: maatiikoo4@gmail.com

Received February 15, 2017; Accepted February 22, 2017; Published February 28, 2017

Citation: Yadesa TM (2017) Inappropriate Use of Antimicrobials and the Determinants among Patients Hospitalized in 3 Hospitals (Mizan, Bonga and Tepi) in Southwest Ethiopia. J Bioanal Biomed 9: 073-079. doi: 10.4172/1948593X.1000157

Copyright: () 2017 Yadesa TM. This is an open-access article distributed under the terms of the Creative Commons Attribution License, which permits unrestricted use, distribution, and reproduction in any medium, provided the original author and source are credited. 
differential diagnoses, complex co-morbidities, lack of training and/or experience, or confidence of physicians in charge, lack of knowledge of local epidemiology of antimicrobial resistance or wrong interpretation of microbiological results [16].

Although commonly practiced, inadequate antimicrobial regimen is ineffective and favours emergence of resistant strains [17]. Each year many patients are hospitalized with adverse drug reactions [18]. Reduction in antimicrobials consumption is clearly important to minimize this problem [19].

In Scandinavian countries Europe, data on the extent of use and type of prescribed antimicrobials as well as the information on antimicrobial resistance levels are continuously collected and analyzed and presented to doctors in primary health care [20]. However, antimicrobial resistance is a growing problem in developing countries [21].

In Ethiopia, there is no launched national controlling system or policy on antimicrobials use; neither do the hospitals including specialized hospitals have their own antimicrobial use guidelines or controlling systems to assure effective treatment and limit the use of broad-spectrum antimicrobials. Therefore, this study aimed to assess the magnitude and patterns of antimicrobial use problems and to identify the associated factors.

\section{Methods and Participants}

\section{Study area and period}

The study was conducted in Bonga, Teppi and Mizan general hospitals which are found in three bordering zones, Keffa, Sheka and Benchi Maji, south west Ethiopia from March 1-30, 2015. The areas have hot and humid climate with high annual rainfall.

\section{Study design}

A prospective observational study design was employed.

\section{Populations}

Source population: All patients admitted at medical wards of Bonga, Teppi and Mizan general hospitals

Target population: All patients admitted at medical wards of Bonga, Teppi and Mizan general hospitals who take antimicrobial(s) or who need one(s).

Study population: Patients admitted at medical wards of Bonga, Teppi and Mizan general hospitals during the study period that fulfilled inclusion and exclusion criteria.

\section{Variables}

Independent variables: Patient related:

- $\quad$ Patient age

- Patient sex

- Co-morbidities

- Concurrent medications

- Financial constraints

- Beliefs/Misconception

\section{Prescriber/Facility/Drug related}

- Status of the prescriber

- Timely laboratory results
- Length of hospital stay

- $\mathrm{CPGs}$

- Antimicrobial category

- Total number of drugs taken

- Availability of antimicrobials

- Medication history

- Availability of culture and sensitivity tests

Dependent variables

- Antimicrobial use problems

\section{Inclusion and exclusion criteria}

\section{Inclusion criteria}

- Patients on any form of antimicrobials

- Those who have indication for any form of antimicrobial(s) treatment, but not on one(s)

- Patients on anti-TB or ART who also take concurrent systemic antimicrobials

- Age greater or equal to 15 years

\section{Exclusion criteria}

- Patients who completed the treatment before or on first day of data collection

- Patients who were admitted for less than $24 \mathrm{~h}$

- Patients on anti-tuberculosis, antiretroviral therapy, viral hepatitis therapy and topical antimicrobials

\section{Data collection process and data quality assurance}

Data collection tools: The antimicrobial therapy was reviewed to assure compliance with the recommendations of the national guidelines or/and evidence based international clinical guidelines. The charts of all hospitalized patients who received an antimicrobial agent was reviewed, and data on patient description, current diagnoses, comorbidities and medications was recorded anonymously in a patient specific protocol using the pre-prepared data abstraction format. Each patient was then asked for compliance related problems and the responses filled to the same checklist.

Data collectors: Two trained pharmacists were involved in collecting the data using the prepared checklist under the supervision of a senior pharmacist in each of the three hospitals.

Pre-test: The data collection tools were pre-tested and checked for completeness and feasibility by the principal investigator before the data collection period for any need of possible amendments. This data, however, were not part of the study results.

Data quality management: To optimize the quality of data collection, the principal researcher closely monitored every steps of data collection throughout the data collection period. Moreover, the Investigators were also committed to resolve any problems faced by the data collectors timely. In addition, the checklists were rechecked by the Investigators for any missed, incorrect and unreadable information whilst collecting data.

\section{Data analysis and interpretation}

The Statistical Package for Social Science (SPSS) programs version 
16.0 for Windows was be used to enter, encode and analyze the collected data. Descriptive statistics, such as frequency and percentage were used to analyze the different types of DTPs identified and their causes as well as to present patient related factors influencing antimicrobials use. The logistic regression model was fit to determine the association between the patient specific factors and the occurrence of the different types of DTPs. Comparison of factors contributing for drug therapy problems at patient level was shown using odd ratios. Statistical significance was considered at $\mathrm{p}$-value $<0.05$.

\section{Ethical consideration}

This study was approved by Institutional Review Board (IRB) of Mizan Tepi University. Official permission was obtained from the hospital before data collection begins. The drug therapy problems identified during the data collection were handled by the Investigators for communication to the respective prescribers for resolution.

\section{Results}

\section{Socio-demographic characteristics of the participants}

This is a prospective study was conducted in Mizan, Tepi and Bonga hospitals of south west Ethiopia involving a total of 291 patients admitted to the medical wards with diagnoses of different types of infectious diseases. The participants were followed daily from date of admission until discharge. Over half $(52.2 \%)$ of them were females, $76(26.1 \%)$ belonged to age group of $25-34$ years and $175(60.1 \%)$ of them were married and the most (74.2\%) used at least one social drug (Table 1).

\section{The health facility factors}

In most of the patients $176(60.5 \%)$ laboratory values to support diagnosis of infection were available within the first two days of hospital admission. None of the 3 hospitals had their own guideline on antimicrobial use and they were identified to particularly use Ethiopian Standard treatment guideline for general hospitals of 2014. However, this guideline did not address management of $63(21.6 \%)$ of the cases (Table 2).

\section{Patient related factors}

Among the 126 reproductive age females in the study population, $31(24.6 \%)$ were either pregnant or breast feeding. On the other hand, $101(34.7 \%)$ of the patients used antimicrobials within the previous three months. About half of the patients (51.3\%) stayed in the hospital for less than 10 days (Table 3 ).

\section{Occurrences of antimicrobial use problems}

A total of 348 antimicrobial containing orders were prescribed for the 291 patients during the 2525 person-days of follow up. At least one antimicrobial use problem was identified among $233(80.1 \%)$ of the patients. The most frequent drug therapy problem type was 'needs additional drug therapy' which was experienced by $91(31.3 \%)$ of the patients followed by 'dosage too low' that incurred by $65(22.4 \%)$ of the patients. The incidence density of antimicrobial use problems was 0.15 problems per person-days. This implies the risk of occurrence of an antimicrobial therapy problem for each patient being about $15 \%$ every day. Similarly, there were identified 1.1 problems per order 1.3 problems per admission (Table 4).

\section{The determinants of antimicrobial use problems}

The binary logistic regression shows that among all the variables studied, the use of at least one social drug (alcohol, tobacco, Khat or

\begin{tabular}{|c|c|c|c|}
\hline Variables & Categories & Frequency & Percentage \\
\hline \multirow{2}{*}{ Sex of the patient } & Female & 152 & 52.2 \\
\hline & Male & 139 & 47.8 \\
\hline \multirow{6}{*}{ Age category } & $15-24$ & 69 & 23.7 \\
\hline & $25-34$ & 76 & 26.1 \\
\hline & $35-44$ & 30 & 10.3 \\
\hline & $45-54$ & 44 & 15.1 \\
\hline & $55-64$ & 40 & 13.7 \\
\hline & $\geq 65$ & 32 & 11.0 \\
\hline \multirow{4}{*}{ Marital status } & Married & 175 & 60.1 \\
\hline & Single & 64 & 22.0 \\
\hline & Widowed & 32 & 11.0 \\
\hline & Divorced & 20 & 6.9 \\
\hline \multirow{7}{*}{ Occupation } & Unemployed & 33 & 11.3 \\
\hline & Student & 32 & 11.0 \\
\hline & Housewife & 31 & 10.7 \\
\hline & Farmer & 119 & 40.9 \\
\hline & Self-employed & 37 & 12.71 \\
\hline & Non-Governmental employee & 5 & 1.7 \\
\hline & Governmental employee & 34 & 11.7 \\
\hline \multirow{4}{*}{ Education level } & Illiterate & 98 & 33.7 \\
\hline & Elementary & 79 & 27.1 \\
\hline & Secondary & 76 & 26.1 \\
\hline & College or above & 38 & 13.1 \\
\hline \multirow{2}{*}{ Social drug use } & Yes & 216 & 74.2 \\
\hline & No & 75 & 25.8 \\
\hline
\end{tabular}

Table 1: The socio-demographic characteristics of patients admitted to medical wards of Mizan Aman, Bonga and Tepi hospitals who were prescribed or needed antimicrobials, from June 10 to August 30, 2015.

\begin{tabular}{|c|c|c|c|}
\hline Variables & Categories & Frequency & Percentage \\
\hline \multirow{2}{*}{$\begin{array}{c}\text { Laboratory results } \\
\text { available within 2 days }\end{array}$} & Yes & 176 & 60.5 \\
\hline National guideline & No & 115 & 39.5 \\
\hline addresses the case & Nes & 228 & 78.4 \\
\hline \multirow{2}{*}{$\begin{array}{c}\text { The infection not confirmed } \\
\text { or unknown }\end{array}$} & Yes & 63 & 21.6 \\
\cline { 2 - 4 } & No & 113 & 38.8 \\
\hline
\end{tabular}

Table 2: The health facility factors related to antimicrobial use among patients admitted to medical wards of Mizan Aman, Bonga and Tepi hospitals that were prescribed or needed antimicrobials, from June 10 to August 30, 2015.

caffeine) $[\mathrm{COR}=2.519(1.372-4.626) ; \mathrm{p}=0.003$ at $95 \%$ C.I.], the total number of drugs used [COR $=2.480(1.272-4.835) ; \mathrm{p}=0.008$ for $3-4$ drugs and $\mathrm{COR}=4.454(2.014-9.849) ; \mathrm{p}=0.000$ for $\geq 5$ drugs at $95 \%$ C.I.] and history of using antimicrobials in the previous 3 months [COR=2.689(1.325-5.456); $\mathrm{p}=0.006$ at $95 \%$ C.I.] were significantly associated with occurrence of at least one antimicrobial use problem (Table 5).

When multivariate logistic regression was done, only the use of social drug $[\mathrm{AOR}=2.549(1.279-5.080)$ at $95 \%$ C.I.; $\mathrm{p}$ value $=0.008)$ ], the use of antimicrobial in the previous 3 months $[\mathrm{AOR}=4.095(1.855$ $9.040)$ at $95 \%$ C.I.; $p$ value $=0.000$ ] and the total number of drugs used $[\mathrm{AOR}=2.997(1.413-6.356) ; \mathrm{p}$ value $=0.004$ for 3-4 drugs and $\mathrm{AOR}=4.653(1.985-10.906) ; \mathrm{p}$ value $=0.000$ for $\geq 5$ drugs at $95 \%$ C.I.] were independently associated with antimicrobial use problems (Table $6)$.

\section{Discussion}

In our current study conducted at 3 hospitals, Mizan Aman, Tepi and Bonga Shawo general hospitals, we identified that no culture and 
Citation: Yadesa TM (2017) Inappropriate Use of Antimicrobials and the Determinants among Patients Hospitalized in 3 Hospitals (Mizan, Bonga and Tepi) in Southwest Ethiopia. J Bioanal Biomed 9: 073-079. doi:10.4172/1948-593X.1000157

\begin{tabular}{|c|c|c|c|}
\hline Variables & Response category & Frequency(N=152) & Percentage \\
\hline \multirow{3}{*}{ Pregnancy or breast feeding } & Pregnant/Breast feeding & $31^{*}$ & 24.6 \\
\hline & Not Pregnant/Breast feeding & $95^{*}$ & 75.4 \\
\hline & Not applicable & 165 & 56.7 \\
\hline \multirow{5}{*}{ Number of comorbidities } & None & 46 & 15.8 \\
\hline & One & 135 & 46.4 \\
\hline & Two & 66 & 22.7 \\
\hline & Three & 28 & 9.6 \\
\hline & Four and above & 16 & 5.5 \\
\hline \multirow{2}{*}{ Medication history } & Yes & 101 & 34.7 \\
\hline & No & 190 & 65.3 \\
\hline \multirow{3}{*}{ Total drugs used } & $\leq 2$ & 85 & 29.2 \\
\hline & 03-Apr & 110 & 37.8 \\
\hline & $\geq 5$ & 196 & 33 \\
\hline \multirow{3}{*}{ Hospital stay in days } & $\geq 5$ & 121 & 41.6 \\
\hline & 06-Oct & 78 & 26.8 \\
\hline & $\geq 11$ & 72 & 24.7 \\
\hline \multirow{4}{*}{ Clinical outcome } & Dead & 23 & 7.9 \\
\hline & Worsened & 53 & 18.2 \\
\hline & Improved & 207 & 71.1 \\
\hline & No change in clinical course & 8 & 2.8 \\
\hline
\end{tabular}

Table 3: Patient/Medical factors related to antimicrobials use among patients admitted to medical wards of Mizan Aman, Bonga and Tepi hospitals who were prescribed or needed antimicrobials, from June 10 to August 30, 2015.

\begin{tabular}{|c|c|c|}
\hline Variables & Total incidents & Prevalence (N \%) \\
\hline Needs additional antimicrobial/s & 94 & 31.3 \\
\hline Dosage too low & 71 & 22.4 \\
\hline Non compliance & 72 & 21.7 \\
\hline Unnecessary antimicrobial/s & 60 & 19.9 \\
\hline Ineffective antimicrobial/s & 46 & 15.8 \\
\hline Dosage too high & 46 & 15.8 \\
\hline Adverse Drug Reaction & 22 & 7.6 \\
\hline Total antimicrobial use problems & 380 & 80.1 \\
\hline \multicolumn{2}{|c|}{ Incidences of antimicrobial (AM) use problems } & Incidences \\
\hline Problems per patient & $380 \mathrm{AM}$ use problems/291 patients & 1.3 Problems per patient \\
\hline Problems per order & $380 \mathrm{AM}$ use problems/348 orders & 1.1 Problems per order \\
\hline Incidence density & $380 \mathrm{AM}$ use problems/2525 person days & 0.15 Problems per person-day \\
\hline
\end{tabular}

Table 4: Types of antimicrobial use problems identified among patients admitted to medical wards of Mizan Aman, Bonga and Tepi hospitals who were prescribed or needed antimicrobials, from June 10 to August $30,2015 . \mathrm{N}$ : Total number of patients in each category; $\mathrm{N} \%$ : The percentage of patients in each category.

susceptibility test was done to guide antimicrobials use. This, in turn, might significantly increase the mortality rate from acute infections; lengthens hospital stays and increase individual patients as well as the health care cost as a whole and more importantly narrows the future alternatives of antimicrobials therapy.

Almost in $113(38.8 \%)$ of the patients, there was uncertainty in the differential diagnosis of the infectious disease until the first antimicrobials were prescribed. This is mainly due to the shortage of resources including: timely laboratory results and radiology services and probably shortage of experts on infectious diseases.

The mortality ratio of $23(7.9 \%)$ in this study is lower compared to previous study in Jimma University specialized hospital of $12.6 \%$ in 2010 [22]. This might be due to the exclusion of non-infectious medical conditions or the gradual improvement in the quality of health care in the region.

At least one type of antimicrobial use problem was identified among 233(80.1\%) while the antimicrobial use was appropriate only among the remaining 58(19.9\%). This level of inappropriate use of antimicrobials is much higher compared to $332(46.7 \%)$ patients in a study by Ceyhan et al. in Turkey [23] but comparable with inappropriateness of 184(73.3\%) in Kyrgyzstan [15]. The former might be attributed to the lower quality of health care in Ethiopia, one of the poorest countries.

The most frequent drug therapy problem type was 'need for additional drug therapy' which accounted for $91(31.3 \%)$ of the patients compared to 1947 (37.9\%) of patients of all types of diseases and drugs in a study by Robert et al. [24]. This might be lower because the need for additional drug therapy most probably is higher for non-infectious and chronic diseases which were excluded from this study. The delay in initiation of effective antimicrobials in acutely ill patients might increase in-hospital mortality.

On the other hand, unnecessary antimicrobial therapy of $44(28.9 \%)$ in this study is comparable to $30 \%$ of unnecessary days of antimicrobial therapy in a study in Cleveland [25]. Accordingly, there is high rate of unnecessary antimicrobials use mainly due to the use of duplicates of broad spectrum antimicrobials combinations whereas a single one or a narrower spectrum antimicrobial would be more reasonable and recommended. This using of unnecessarily broader spectrum and duplicates of antimicrobials with overlapping spectrum of activity and similar mechanism of action will clearly contribute for the emergence and dissemination of antimicrobial resistant microorganisms. 
Citation: Yadesa TM (2017) Inappropriate Use of Antimicrobials and the Determinants among Patients Hospitalized in 3 Hospitals (Mizan, Bonga and Tepi) in Southwest Ethiopia. J Bioanal Biomed 9: 073-079. doi:10.4172/1948-593X.1000157

\begin{tabular}{|c|c|c|c|c|c|}
\hline \multirow[b]{2}{*}{ Variables } & \multirow{2}{*}{ Categories } & \multicolumn{2}{|c|}{ DTP } & \multirow{2}{*}{$P$ value } & \multirow{2}{*}{$\begin{array}{c}\text { COR }(95 \% \mathrm{Cl}) \text { for } \\
\text { DTP }\end{array}$} \\
\hline & & No & Yes & & \\
\hline \multirow{6}{*}{ Age } & $15-24$ & 16 & 53 & - & 1 \\
\hline & $25-34$ & 18 & 58 & 0.944 & $0.973(0.451-2.100)$ \\
\hline & $35-44$ & 3 & 27 & 0.137 & $2.717(0.728-10.144)$ \\
\hline & $45-54$ & 8 & 36 & 0.527 & $1.358(0.526-3.507)$ \\
\hline & $55-64$ & 9 & 31 & 0.934 & $1.040(0.411-8.432)$ \\
\hline & $\geq 65$ & 4 & 28 & 0.217 & $2.113(0.644-6.929)$ \\
\hline \multirow{2}{*}{ Sex } & Female & 36 & 116 & 0.096 & $0.606(0.336-1.092)$ \\
\hline & Male & 22 & 117 & - & 1 \\
\hline \multirow{7}{*}{ Occupation } & Unemployed & 8 & 25 & 0.146 & $0.379(0.102-1.401)$ \\
\hline & Student & 5 & 27 & 0.556 & $0.655(0.160-2.680)$ \\
\hline & Housewife & 15 & 16 & 0.001 & $0.129(0.037-0.453)$ \\
\hline & Farmer & 18 & 101 & 0.512 & $0.680(0.215-2.153)$ \\
\hline & Self-employed & 8 & 26 & 0.162 & $0.394(0.107-1.454)$ \\
\hline & Non-governmental employees & 0 & 5 & 0.999 & $\mathrm{NC}$ \\
\hline & Governmental employee & 4 & 33 & - & 1 \\
\hline \multirow{4}{*}{ Marital status } & Single & 15 & 49 & - & 1 \\
\hline & Married & 38 & 137 & 0.776 & $1.104(0.559-2.180)$ \\
\hline & Widowed & 3 & 29 & 0.108 & $2.959(0.789-11.099)$ \\
\hline & Divorced & 2 & 18 & 0.206 & $2.755(0.573-13.259)$ \\
\hline \multirow{2}{*}{ Social drug use } & No & 24 & 51 & - & 1 \\
\hline & Yes & 34 & 182 & 0.003 & $2.519(1.372-4.626)$ \\
\hline \multirow{4}{*}{ Education level } & Illiterate & 16 & 82 & 0.106 & $0.285(0.062-1.304)$ \\
\hline & Elementary & 21 & 58 & 0.015 & $0.153(0.034-0.694)$ \\
\hline & Secondary & 19 & 57 & 0.020 & $0.167(0.037-0.759)$ \\
\hline & College or above & 2 & 36 & - & 1 \\
\hline \multirow{2}{*}{$\begin{array}{l}\text { Confirmation of diagnosis by } \\
\text { laboratory }\end{array}$} & No & 22 & 93 & 0.782 & $1.087(0.602-1.964)$ \\
\hline & Yes & 36 & 140 & - & 1 \\
\hline \multirow{2}{*}{ National guideline addresses the case } & No & 8 & 55 & 0.109 & $1.931(0.863-4.321)$ \\
\hline & Yes & 50 & 178 & - & 1 \\
\hline \multirow{2}{*}{ Uncertain/unknown diagnosis } & No & 42 & 136 & - & 1 \\
\hline & Yes & 16 & 97 & 0.052 & $1.872(0.995-3.522)$ \\
\hline \multirow{3}{*}{ Pregnancy } & No & 24 & 71 & - & 1 \\
\hline & Yes & 5 & 26 & 0.298 & $1.758(0.607-5.089)$ \\
\hline & NA & 29 & 136 & 0.140 & $1.585(0.859-2.924)$ \\
\hline \multirow{6}{*}{ Number of comorbidities } & None & 13 & 33 & - & 1 \\
\hline & One & 30 & 105 & 0.407 & $1.379(0.645-2.946)$ \\
\hline & Two & 10 & 56 & 0.095 & $2.206(0.871-5.591)$ \\
\hline & Three & 5 & 23 & 0.315 & $1.812(0.568-5.785)$ \\
\hline & Four & 0 & 12 & 0.999 & $\mathrm{NC}$ \\
\hline & Five and above & 0 & 4 & 0.999 & $\mathrm{NC}$ \\
\hline \multirow{2}{*}{ Medication history } & No & 47 & 143 & - & 1 \\
\hline & Yes & 11 & 90 & 0.006 & $2.689(1.325-5.456)$ \\
\hline \multirow{3}{*}{ Total drugs used } & $\leq 2$ & 29 & 56 & - & 1 \\
\hline & $3-4$ & 19 & 91 & 0.008 & $2.480(1.272-4.835)$ \\
\hline & $\geq 5$ & 10 & 86 & 0.000 & $4.454(2.014-9.849)$ \\
\hline \multirow{3}{*}{ Hospital stay in days } & $\leq 5$ & 18 & 74 & - & 1 \\
\hline & $6-10$ & 25 & 96 & 0.844 & $0.934(0.474-1.839)$ \\
\hline & $\geq 11$ & 15 & 63 & 0.956 & $1.022(0.476-2.191)$ \\
\hline
\end{tabular}

Table 5: Univariate logistic regression analysis for the determinants of antimicrobial use problems among patients admitted to medical wards of Mizan Aman, Bonga and Tepi hospitals who were prescribed or needed antimicrobials, from June 10 to August 30, 2015. NC: Not calculable; COR: Crude Odd ratio; DTP: Drug therapy problems; ETB: Ethiopian birr; NA: Women other than the child-bearing age (15-49) and all males.

Moreover, the use of antimicrobials for non-infectious diseases such as, asthma exacerbation, heart failure, cor-pulmonale and noninfectious diarrhea in the absence any laboratory test suggesting the infection was found to be rampant. This practice does also significantly contribute for excessive use of antimicrobials further contributing for antimicrobial resistance.

The prevalence of 'dose too low' of $65(22.4 \%)$ of antimicrobials in this study is comparable with $1436(28 \%)$ of a large multi-centered study by Robert et al. [24]. In this study, the most common causes for 'Dose too low' were drug interactions, too low dose and shorter duration of antimicrobial therapy. These problems might contribute to the emergence of antimicrobial resistance.

The prevalence of non-compliance of $63(21.7 \%)$ in this study was found to be higher compared to $19(13.19 \%)$ in Jordan [26] probably 


\begin{tabular}{|c|c|c|c|c|c|}
\hline \multirow{2}{*}{ Variables } & \multirow{2}{*}{ Category } & \multicolumn{2}{|c|}{ AUP } & \multirow{2}{*}{ P value } & \multirow{2}{*}{ AOR (95\% C.I.) } \\
\hline & & No & Yes & & \\
\hline \multirow{2}{*}{ Medication history } & No & 24 & 51 & - & 1 \\
\hline & Yes & 34 & 182 & 0 & $4.095(1.855-9.040)$ \\
\hline \multirow{2}{*}{ Social drug use } & No & 24 & 51 & - & 1 \\
\hline & Yes & 34 & 182 & 0.008 & $2.549(1.279-5.080)$ \\
\hline \multirow{3}{*}{ Total drugs used } & $\leq 2$ & 29 & 56 & - & 1 \\
\hline & 03-Apr & 19 & 91 & 0.004 & $2.997(1.413-6.356)$ \\
\hline & $\geq 5$ & 10 & 86 & 0 & $4.653(1.985-10.906)$ \\
\hline
\end{tabular}

Table 6: Multivariate logistic regression analysis for the determinants of antimicrobial use problems among patients admitted to medical wards of Mizan Aman, Bonga and Tepi hospitals who were prescribed or needed antimicrobials, from June 10 to August 30, 2015. AOR: Adjusted odd ratios; CPG: Clinical practice guidelines; AUP: Antimicrobial use problems.

due to the fact that the patients spend 'out of pocket money' on the health expenditures and buying drugs in the hospitals like any other hospitals in Ethiopia. Moreover, because of the low income level of the patients, non-compliance was mainly related to unaffordability, $50 / 63(79.4 \%)$ in this study.

Similarly, the prevalence of 'Ineffective AM therapy' was 46(15.8\%) which is much lower compared to 97 (32.9\%) in Kyrgyzstan [15] and 71(49\%) in Jordan [26]. The reason for this low rate of ineffective antimicrobial therapy' may be due to the high rate of the use of duplicates of broad spectrum antimicrobials in this study.

In this study the binary logistic regression shows that there is no significant association between the occurrence of antimicrobial use problem and socio-demographic variables including: age, sex, occupation, educational level and marital status. This is comparable with a study by Blix et al. which found that neither of age nor gender was an independent risk factor for the occurrence of DTPs [27].

On the other hand, a significant association $[\mathrm{AOR}=2.549(1.279$ 5.080 ) at $95 \%$ C.I.; $p$ value $=0.008)]$ was observed between the use of at least one social drug (alcohol, tobacco, Khat or caffeine) and the probability of occurrence of at least one drug therapy problem. This might be attributed to the use of these unnecessary drugs by itself as well as the probable result of their uses on non-compliance and contribution for drug interaction.

Medication history, the use of antimicrobial in the previous 3 months was the other variable significantly associated [AOR=4.095(1.8559.040 ) at $95 \%$ C.I.; $p$ value $=0.000$ ] was the other identified determinant of antimicrobial use problem. This might be due to the fact that many prescribers did not assess and consider which antimicrobials the patients had taken previously. However, the past antimicrobial therapy might positively or negatively affect the current selection by influencing the safety and effectiveness of current treatment.

Finally, the total number of drugs used was significantly associated $[\mathrm{AOR}=2.997(1.413-6.356)$; $\mathrm{p}$ value $=0.004$ for $3-4 \mathrm{drugs}$ and $\mathrm{AOR}=4.653$ (1.985-10.906); $\mathrm{p}$ value $=0.000$ for $\geq 5$ drugs at $95 \%$ C.I.] with antimicrobial use problems. A case that used 3-4 drugs and 5 or more drugs was about 2.997 and 4.653 times more likely to encounter these problems compared to those who used 2 or less drugs. This association might be explained by the fact that the more the number of drugs used, the higher the probability of drug interactions with possible effects on safety or efficacy or both as well as the possible increased probability of non-compliance due to inconvenience, safety or cost issues. For one example, failure to check for adverse drug interactions contributed for $25.5 \%$ of all the medication errors in a study in a tertiary hospital in Nigeria [28]. This association is comparable with a study by Blix et al. [29] and another study by Haugbølle and Sørensen [30] both of which independently showed DTPs increased with the increase in number of drugs used.

\section{Conclusion and Recommendations}

\section{Conclusion}

Generally, the antimicrobials use problems in the medical wards of Mizan Aman, Tepi and Bonga Shawo hospitals is higher compared to most of the studies from developed countries but comparable to those in developing countries. At least one antimicrobial use problem was prevalent among most of the patients. Most of the problems were due to excessive use or delay of initiation of effective antimicrobials, lack of confirmation of infection, unaffordability of antimicrobial therapy and deviation in selection of antimicrobials from either national or the evidence based guidelines of IDSA. The independent determinants of antimicrobial use problems were the total number of drugs used, use of social drugs and the previous use of antimicrobials.

\section{Recommendations}

Each of the 3 hospitals should strengthen the microbiological services to help preventing antimicrobial resistance. The health professionals in the hospitals should manage how to accurately and comprehensively obtain medication history and prescribe accordingly. The local health sectors and collaborating NGOs should organize the effort towards raising public awareness on the determinant effects of social drugs and their effect on drug therapy. The hospitals DTCs should closely monitor the unnecessary duplications of drug therapies by strengthening clinical pharmacy services, providing due trainings and by devising strategies to promote rational use of antimicrobials and control the use.

\section{Acknowledgements}

I would like to thank Mizan Tepi University of Ethiopia for financially sponsoring this study. I would also like to thank my colleagues Mr. Muktar Sano and Mr. Tarekegn Tesfaye and the administrative and technical staff of the Bonga, Mizan and Tepi hospitals for their support and cooperation during conducting this study.

\section{References}

1. Aryanti R, Hilbrand H (2002) Determinants of Antimicrobial Use in the Developing World. Child Health Research Project Special Report 4: 5-22.

2. Continuing Education Discussion Guide (2011) Implementing Antimicrobial Stewardship Programs in Health Systems pp: 2-11.

3. WHO (2007) A safer future: global public health security in the $21^{\text {st }}$ Century The World Health Report.

4. Spellberg B, Blaser M, Guidos RJ, Boucher HW, Infectious Diseases Society of America (IDSA), et al. (2011) Combating Antimicrobial Resistance: Policy Recommendations to Save Lives. Clin Infect Dis 52: S397-S428.

5. Al-Tawfiq JA, Stephens G, Memish ZA (2010) Inappropriate antimicrobial use and potential solutions: a Middle Eastern perspective. Expert Rev Anti Infect Ther 8: 765-774.

6. Costelloe C, Metcalfe C, Lovering A, Mant D, Hay AD (2010) Effect of antibiotic 
Citation: Yadesa TM (2017) Inappropriate Use of Antimicrobials and the Determinants among Patients Hospitalized in 3 Hospitals (Mizan, Bonga and Tepi) in Southwest Ethiopia. J Bioanal Biomed 9: 073-079. doi:10.4172/1948-593X.1000157

prescribing in primary care on antimicrobial resistance in individual patients: systematic review and meta-analysis. BMJ 340: c2096.

7. Vlahović-Palcevski V, Dumpis U, Mitt P, Gulbinovic J, Struwe J, et al. (2007) Benchmarking antimicrobial drug use at university hospitals in five European countries. Clin Microbiol Infect 13: 277-283.

8. Cantón R, Horcajada JP, Oliver A, Garbajosa PR, Vila J (2013) Inappropriate use of antibiotics in hospitals: The complex relationship between antibiotic use and antimicrobial resistance. Enferm Infec Microbiol Clin 31: 3-11.

9. Haq E (2010) Antibiotic Resistance; Contributing Factors. JUMDC 1: 1-3.

10. Van der Velden LJ, Tromp M, Bleeker-Rovers CP, Hulscher M, Kullberg BJ, et al. (2012) Non-adherence to antimicrobial treatment guidelines results in more broad-spectrum but not more appropriate therapy. Eur J Clin Microbiol Infect Dis 31: 1561-1568.

11. Seikh FA, Mohammed FR, Jamalluddin AR, Nordin MS, Satwi S, et al. (2012) Antimicrobial use and factors influencing prescribing in medical wards of a tertiary care hospital in Malaysia. IJSET 1: 274-284.

12. Van der Meer JM, Gyssens IC (2001) Quality of antimicrobial drug prescription in hospital. Clin Microbiol Infect 7: 12-15.

13. Kunin CM, Tupasi T, Craig WA (1973) Use of antibiotics. A brief exposition of the problem and some tentative solutions. Ann Intern Med 79: 555-560.

14. Siritree S, Anita KW, Ruangthip T, Dennis RD, Chitr SA (2005) Patterns, appropriateness, and predictors of antimicrobial prescribing for adults with upper respiratory infections in urban slum communities of Bangkok. Southeast Asian J Trop Med Public Health 36: 489-497.

15. Kambaralieva B, Bozgunchiev M, Zurdinov A, Harun-or-rashid MD, Junichi S (2011) An assessment of antibiotics prescribed at the secondary health-care level in the Kyrgyz republic. Nagoya J Med Sci 73: 157-168.

16. Cusini A, Rampini SK, Bansal V, Ledergerber B, Kuster SP, et al. (2010). Different Patterns of Inappropriate Antimicrobial Use in Surgical and Medical Units at a Tertiary Care Hospital in Switzerland: A Prevalence Survey. PLoS ONE 5: e14011.

17. Emmanuel ED (1997) Inappropriate Antibiotic Use in the Philippines. Phil J Microbiol Infect Dis 26: 77-87.

18. Granowitz EV, Brown RB (2008) Antibiotic Adverse Reactions and Drug Interactions. Crit Care Clin 24: 421-442.
19. Hayashi Y, Paterson DL (2011) Strategies for Reduction in Duration of Antibiotic Use in Hospitalized Patients. Clin Infect Dis 52: 1232-1240.

20. Katarina I, Emil J, Vesna S (2012) Social-economic factors and irrational antibiotic use as reasons for antibiotic resistance of bacteria causing common childhood infections in primary healthcare. Eur J Pediatr 171: 767-777.

21. Dagnew M, Yismaw G, Gizachew M, Gadisa A, Abebe T, et al. (2013) Bacteria profile and antimicrobial susceptibility pattern in septicemia suspected patients attending Gondar University Hospital, Northwest Ethiopia. BMC Res Notes 6: 283.

22. Ali E, Woldie M (2010) Reasons and Outcomes of Admissions to the Medica Wards of Jimma University Specialized Hospital, Southwest Ethiopia. Ethiop J Health Sci 20: 113-120.

23. Ceyhan M, Yildirim I, Ecevit C, Aydogan A, Ornek A, et al. (2010) Inappropriate antimicrobial use in Turkish pediatric hospitals: A multicenter point prevalence survey. Int J Infect Dis 14: e55-e61.

24. Robert JC, Linnda MS, Peter CM, Cipolle R (2008) Pharmaceutical care practices: the clinician's Guide ( $2^{\text {nd }}$ edn.), McGraw-Hill Companies, Minnesota, USA.

25. Michelle TH, David CA, Nilam PP, Meghan KL, Curtis JD (2003) Unnecessary Use of Antimicrobials in Hospitalized Patients: Current Patterns of Misuse with an Emphasis on the antianaerobic Spectrum of Activity. Arch Intern Med 163: 972-978.

26. Toubes E, Singh K, Yin D, Lyu R, Glick N, et al. (2003) Risk Factors for Antibiotic-Resistant Infection and Treatment Outcomes among Hospitalized Patients Transferred from Long-Term Care Facilities: Does Antimicrobial Choice Make a Difference? Clin Infect Dis 36: 724-730.

27. Blix HS, Viktil KK, Moger TA, Reikvam A (2008) Risk of drug-related problems for various antibiotics in hospital: assessment by use of a novel method Pharmacoepidemiol Drug Saf 17: 834-841.

28. Ajemigbitse AA, Omole MK, Ezike NC, Erhun WO (2014) Assessment of the knowledge and attitudes of intern doctors to medication prescribing errors in a Nigeria tertiary hospital. J Basic Clin Pharma 5: 7-14

29. Blix HS, Viktil KK, Reikvam A, Moger TA, Hjemaas BJ, et al. (2004) The majority of hospitalized patients have drug-related problems: results from a prospective study in general hospitals. Eur J Clin Pharmacol 60: 651-658.

30. Haugbølle L, Sørensen E (2006) Drug-related problems in patients with angina pectoris, type-2 diabetes and asthma-interviewing patients at home. Pharm World Sci 28: 239-247. 